$\mathbb{T}$ periodica polytechnica

\author{
Social and Management Sciences \\ 19/1 (2011) 37,41] \\ doi: 10.3311/pp.so.2011-1.05 \\ web: http://www.pp.bme.hu/so \\ (c) Periodica Polytechnica 2011
}

RESEARCH ARTICLE

\section{Influence of social networking for enterprise's activities}

Emese Tokarčíková

Received 2011-01-07

\begin{abstract}
All kinds of advantages, which increase an enterprise's competitiveness and profit levels, are welcome by most subjects in business environments. Currently professionally oriented social networks present one of these potential sources, which offer comparative advantages not only for individuals but also for companies, industrial enterprises and organizations of various kinds. It is because social networking can offer numerous benefits that could help to increase employment expand business activity or generate new business opportunities. The important fact is that social networking services are free, so the costs of their comprehensive use by individuals or businesses are minimal compared with the benefits flowing from them. The future destiny of the development of social networking services is open ended. Today we already know that Internet and mobile technologies are available to the general public. Their positive impact on business and employment activities for the business environment is definitely not negligible.
\end{abstract}

\section{Keywords}

social networking $\cdot$ business environments · business opportunities $\cdot S N$ 's advantages and disadvantages $\cdot$ marketing tools

\section{Acknowledgement}

This work has been supported by the grant VEGA 1/0149/09 Formation of flexible system determining growth of the value of enterprise flowing from analyse relevant attributes by using classical and modern approaches and methods. JEL CLassification: D22, D80.

\section{Emese Tokarčíková}

Department of Macro and Microeconomics, Faculty of Management Science and Informatics, University of Žilina, Univerzitná 8215/1, 01026 Žilina, Slovakia

e-mail: Emese.Tokarcíkova@fri.uniza.sk

\section{Introduction}

A social network is an interconnected structure made by individuals or organizations, which involves through forming social groups by one or more specific types of relationships. It transmits information between registered memberships. The growth and development of information and communication technologies (ICTs) allowed the creation and existence of social networking ( $\mathrm{SN})$, through the Internet and by mobile handsets. It is because "the Internet is more than a medium, it's a new space for communication, a new environment in which there are types of communication like classic mass communication. In addition, there are also interpersonal or cluster communication" (Rankov, $2006[8]$ ). As with many novelties, SN first became popular among young people and scholars, simply as a way to maintain contacts and exchange information with fellow students, colleagues, friends or like-minded individuals. Personal meetings are still primary, paramount and important in interpersonal relationships, but the virtual SN allows improving and accelerating the content and dimensions of these relationships. Research has shown that social networks operate on many levels, from families up to the whole society. SNs also play a critical role in determining means of problems solutions, in organizational development and present a new way for individuals to be successful in achieving their goals.

\section{Types of social networks and their odds}

Creating various types of relationships, contacts and communications by using a SN is today a very popular way of spending time, especially among young people. Fast Internet and mobile connections are widely available, people with good computer skills and number of mobile users daily increase. It means that the information exchange facilitaties creating contacts and cooperation in various areas of life (hobbies, business, science, etc.) can be implemented with relatively little effort. Technically social networks are "web-based services that allow individuals to (1) construct a public or semi-public profile within a bounded system, (2) articulate a list of other users with whom they share a connection, and (3) view and traverse their list of connections and those made by others within the system" (Boyd-Ellison, 
2007 [1]). It means that besides written text and voices call our interpersonal communication may also have additional multimedia content such as video, video messages or large photo albums with high quality photos. In spite of the fact, that registration in some SNs is allowed only for persons or organizations that obtained an invitation from an actual member, the number of memberships of all social networks has grown rapidly since its launch. Social networking is popular mainly between young generations.

In general SNs can be external SNs (open/public and available to all) or internal SNs (closed/available only to a private community). We recognize by orientation:

- SNs serving more or less for leisure and entertainment. Registered users of these communities get a chance to add information about themselves, contact other members of the community, discuss and build a reputation. They can have different references, share information privately and publicly, jollify (online games, knowledge or personality tests), upload unlimited photos and photo albums with comments. Also they can share videos, send video messages, create blogs, organize meetings, create a diary, or just to chat, etc. Also they can create smaller specialised communities with common interests. The best known generic social networks are e.g. Facebook, Twitter, MySpace.com, Windows Live Spaces or hi5 etc. In the Slovak Republic we have SN sites like unister.sk and mojiznami.sk and in the Czech Republic SN sites spoluzaci.cz, lide.cz and libimseti.cz.

- commercially and industrially oriented SNs, which are used primarily for creating and establishing professional contacts. They give a wide scope for professional discussions, to exchange ideas and to seek business opportunities. They create a good tool for experts, who need business guidance or searching for employees with specialized job skills. The most popular of this kind of social networks are LinkedIn, XING and Joblife. Also well known are SNs for groups of people (employees) inside a company, organization or association.

The latest survey about social networking trends in Europe made by comScore, Inc. studied the SN penetration among internet users of 16 European countries. Fig. 1 demonstrates results of this survey.

The survey was orientated to European Social Networking's Reach by Country and found out, that „of the 282.7 million European Internet users of age 15 and older who went online via a home or work computer in December 2008, 211 million visited a social networking site - representing a penetration of 74.6 percent " (comScore, online [13]). While the highest level of SN's penetration was in the United Kingdom with 29,3 million visitors $(79,8 \%)$ the lowest $\mathrm{SN}$ reach was in Austria with 2,1 million visitors $(49,7 \%)$

\section{The influence of social networking on enterprise's activities}

The comparative advantage of social networking is real and includes many areas of business environment. The most important reason is that Internet knows no borders or distance and thus the benefits of virtual communication are limited to the technology and the time spent at the computer. The other main reasons are that utilization of a SN save time and money, because most $\mathrm{SN}$ sites and services are free and fast. Fig. 2 illustrated the main areas of exploitation of social networking in business environment.

\subsection{Marketing and advertisement}

Social networking collects a group of people with similar interests or communities of friends of certain age, education or particular city, which can be targeted by offering goods, services or ideas, and allows creating effective marketing tools for the enterprise. Social networking sites can be used by merchandisers, by brands, by companies, by musicians and by all types of organizations to create free information availability. Users as fans can join other fans of particular goods and business activities. This "fan club" can discuss and react to goods or services. SNs make it possible to get customer feedback immediately, in near-real-time. In addition, members of the community can share information and provide recommendations and positive assessments of their friends or friends located in the same SN community. So the whole world can became our customer and at the same time, "marketing activities" orientated to product or service can be made by satisfied customers. This word-ofmouth marketing is an easy and a cost-efficient form of promotion. Moreover future SN's investments can create possibilities in introducing charge services, i.e. paid advertisement appearing randomly, or according to a group's theme or respectively as a specific user's request. A variety network's statistics types (demographics, popularity of various groups or communities) already offer valuable and free information for marketing specialists about what their customers need, what their interest is, etc. Some companies even invest in the development of software for monitoring and analysis of SN context, which customers use when writing on SNs sites. The aim of these activities is to use this data and information for targeted advertising. By opinion of experts (profit, online), the company should follow the next steps:

- to group of product's supporters

- to group of enterprise's supporters,

- if they exist, to maintain contact with them,

- to include the largest SN's sites in its marketing strategies,

- to monitor the ongoing news in this area one to obtain fast feedback

- to learn about other interests of their supporters (customers). 


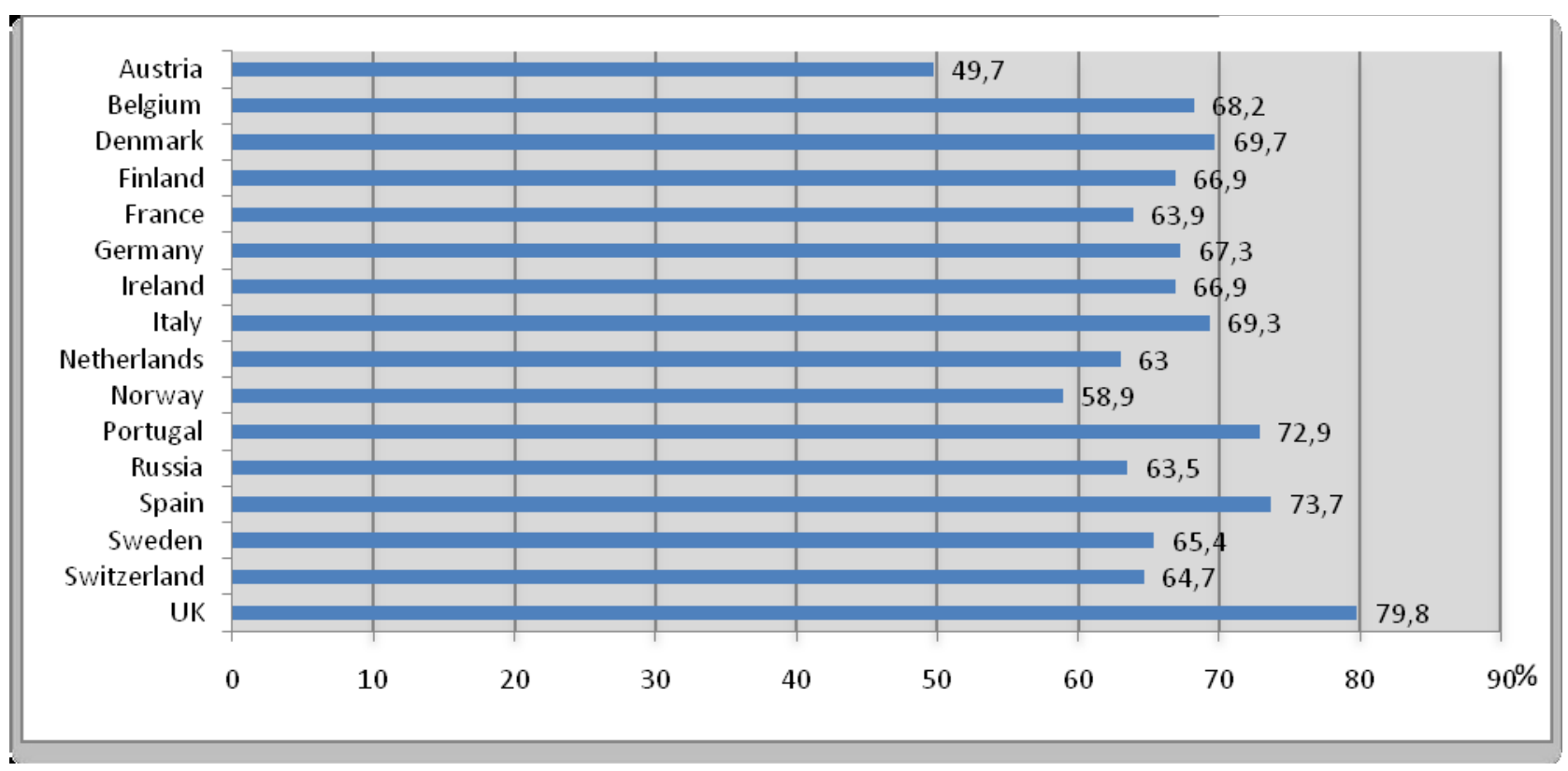

Fig. 1. SN category reach of country's total internet audience (2008). Source: comScore, World Metrix

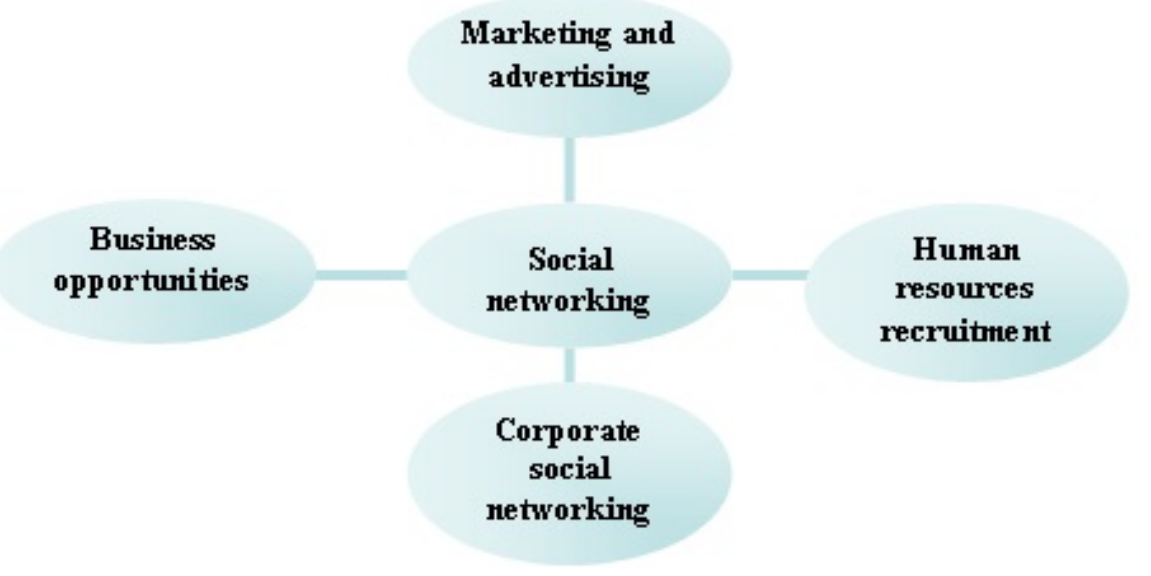

Fig. 2. Influence of social networking in business environment

Follow-up collection, sorting and evaluation of SN's information, i.e. definition of user 's structure, demographics, age, networks, and other factors allow assessing the effectiveness advertising campaigns based on the structure of the SN's community.

\subsection{Human resources - recruitment}

Today many enterprises have specialists in human resources (HR) that search for profiles in SN sites to recruit new colleagues. According to Robert Half International from a poll of 150 senior executives from the biggest US companies, nearly $2 / 3$ of them will use social networking sites for their hiring efforts. HR managers can create their own specific database of specific contacts, because the networks make it possible to locate them directly (according to profiles, school attendance, capabilities, experiences, published works), or indirectly, through recommendations (friends, colleagues, supervisors, trainers). If the HR manager can not find a searched specialist, the networks offer the possibility to write a blog (website). Than in blog's responses somebody can apply for the position or recommend someone else. Currently the increasing numbers of existing and hidden SN links have a greater potential than do traditional websites (databases) of recruitment agencies or job portals. Another advantage is that in some cases personal interviews may take place in more comfortable atmosphere, because the participants "had met" on the network. The other advantage of recruitment on SN's is that the Internet does not know borders. The only restriction is dependant on different national legislation and regulations. To search profiles and to reach interesting candidates is becoming commonplace, but it is still not used by many organizations. HR managers in general use SNs quickly and reasonably because their frequent job offers may also harass the potential employees. In the other case we can not forget that virtual profiles do not replace personal job interviews because the person behind the monitor may not be identical with declared candidate SN portrait. Nevertheless, according to american sociologist Mark Granovetter at Stanford University: "50 to 70 percent of jobs employees obtain by using some kind of "network"then by using connections with people they previously worked 
or met with them". " Individuals use social contacts and networks already in place, and need not invest in constructing them, the cost is less than that of more formal search intermediaries" (Granovetter, 2005 [5]). According to Mark Mehler from CareerXroads, a ,person using social networking sites to get a job chances increase from $1 / 500$ to $1 / 35$. “(CareerXroads, 2009 [11])

\subsection{Business opportunities}

Social networks are great tools for interactive business. From their advantages may benefit small and large firms for their future expansion, or ordinary small entrepreneurs as registered users. Built-in search services of SNs make it possible to search commercial, industrial information and issues dealing with a particular task. You can also search for specific companies and firms from different industries and view user recommendations and comments. Business opportunities can be worldwide or oriented towards specialized customers' needs. By identification of conditions and needs, first-hand business activities can substitute ,stone“shops and postal services, or to develop different environmental projects, etc. Using SN enterprises can save time and travel costs, which makes their logistics more flexible and efficient. The amount of relevant information in the world is growing exponentially and the levels of human knowledge are changing rapidly. Although our own experiences are irreplaceable, it is not conceivable that everyone could try everything. Therefore we must also draw from other people's experiences and knowledge. Professional SNs are an ideal form for this type of "education". Experts argue that "in an atmosphere encouraging new initiatives, individuals and teams can compare their own current direction and the results of the commitments they took, regardless of whether those existing in the plans or in the form of a continuous dialogue on finding new business directions. (Vodák - Kucharčíková, 2007 [9]).

\subsection{Corporate social networking}

One form of social networking that is growing in popularity is corporate level social networking. It is a network area, where employees can form relationships with other employees inside the enterprise, or with other people in the industry. It is a new tool, which has made it nearly effortless to meet and keep in touch with new people online in same profession or in a profession where they have needs for advice or new knowledge. SNs allow learning about people with diverse opinion and having exposure to multiple points of view. Ultimately, this exposure can help employees and employers to learn to look at things from different angles, and be more tolerant of other people's opinions. "Some companies are already using internal social networks to create knowledge maps of their employee skill sets and are combining them with unified communications to enable rapid access. Using this model, employees can quickly tap into organizational expertise as needed. These internal social networks will have great value as businesses become more geographically distributed. Users will maintain rich profiles of their own skills on internal websites and make themselves available to share their expertise as needed. "(Gillin, 2008 [4]) The $\mathrm{SN}$ is also a perfect HR tool to obtain and check references and build a reputation in a professional field. Networks offer verbal references for ceo's, trainers, supervisors and colleagues or to confirm the authenticity of the graduation dates, work experience or reputation. Furthermore, an HR manager knows that "the praise, or recognition of positive moment in employee's performance from the side of manager, increases always an appetite and zest for work, a feeling of satisfaction from exerted effort, and in this way, also increases a total mood for voluntary harmonization of individual goals of employees and managers with the goals and objectives of the organization." (BláškováGrazulis, 2009, [2])

\section{Discussion and the future of social networking}

New innovations from new technologies, methods and opportunities can bring significant benefits to an enterprise. Also with their nature and effects in production and services enable communicatively and informatively faster connections of international markets and economies. (Kucharčiková et al., 2011 [7]. But not all influences are only positive and also besides benefits there are existing outstanding problems too. In the case of social networking we can find the following negative influences and unsolved problems:

- How much time is it „effective“ to spend on social networking?

- How much information is safe or desirable to give away about yourself or another colleague?

- How does sort information according to quality, relevance and authenticity?

- Can customer conversation replace marketing?

- How to avoid SN's harassment? Is there good laws and legislative protection?

- How to avoid a smear campaign? Is there good law and legislative protection?

- How much SN time is personal?

- How strong is the privacy protection of users?

- How dangerous is the sharing through gossip and potential abuse of the services?

Research and scholar studies in these areas which can give answers to these questions and enable filtering out problem areas will yield significant benefits. 


\subsection{Future trends of social networking}

With new technology we use new tools to satisfy ancient needs and learn to use them with our limited cognitive capabilities. Examples of these can be the information seeking, communicating and dependency/addiction functions of Internet use or the differentiated use of different media. The increasing popularity of social networking between users and advantages of new mobile technologies are increasing pressure to create $\mathrm{SN}$ sites based on concept of ,to be in real time“ and „location based “. Current Internet SN sites (i.e. MySpace or Facebook) are turning mobile and create mobile virtual communities using the mobile phone for connection. Mobile SNs then create enormous challenges and opportunities for new marketing and business channels. ABI Research's study "Location-based Mobile Social Networking" offers insight into trends, social networking features, drivers, barriers. It is includes detailed descriptions of solutions and market players, with special focus on business models. It also provides recommendations to all major players and shipment and revenue forecasts per region and per locationbased social networking type. (ABIresearch, online). Following Fig. 3 shows a mobile social networks value map published by Matt Jansen on letstalk website.

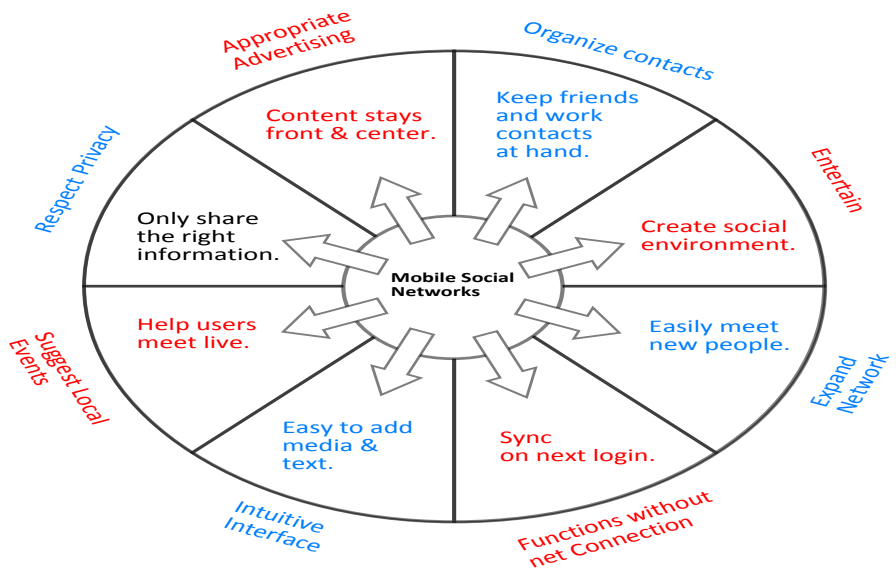

Fig. 3. Mobile social networks value map. Source: http://www.letstalk.com

\section{Conclusion}

The future question appears when the usage of social network will reach its peak. Will SNs turn out to be a bubble similar to the Internet bubble? The fact remains that social networks and online technologies now altering the perception of how people and managers perceive information and make decisions. They allow individuals to build mutual trust, helping them to lead to high-quality economic activities, leading to greater efficiencies and competitiveness and eventually having capital embedded in these communities. Groups of companies, produces a profit ,which is the basic motive of every business decision-making criteria and can be the basis for economic interest of employ-

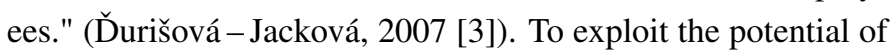
social networks is a highly effective form of communication in terms of labour in, business addicted and social activities can in- fluence and guide successful economic development. We hope that our article described here will help build a foundation for future investigation of these and other important issues surrounding social network sites.

\section{References}

1 Boyd D, Ellison N, Social network sites: Definition, history, and scholarship, Journal of Computer-Mediated Communication(13), posted on 2007, 210-230, DOI 10.1111/j.1083-6101.2007.00393.x, (to appear in print).

2 Blašková M, Grazulis V, Motivation of Human Potential: Theory and Practice, Publishing Centre of Mykolas Romeris University, Vilnius, 2009., ISBN 978-9955-19-155-1.

3 Ďurišová M, Jacková A, Podnikové financie: Business finance, EDIS, Vydavatel'stvo ŽU, Žilina, 2007. isbn=978-80-8070-661-6.

4 Gillin P, Mobile Social Networking: The New Ecosystem, Computerworld Communications Brief, (2008.), http://na.blackberry.com/ ataglance/get_the_facts

5 Granovetter $\mathbf{M}$, The Impact of Social Structure on Economic Outcomes, Journal of Economic Perspectives, 19(1), (2005), 33-50, DOI 10.1257/0895330053147958. Winter.

6 Krajcsi A, Pléh C, Kovács K, Habits of communication of internet users, Periodica Polytechnica Ser. Soc. Man. Sci., 11(1), (2003), 27-33.

7 Kucharčíková A, Tokarčíková E, Ďurišová M, Jacková A, Kozubíková Z, Vodák J, Efektivni výroba: vyuvejte výrobni faktory a připravte se na změny na trzích, Computer Press, (2011), 344.

8 Rankov P, Informačná spoločnost': perspektívy, problémy, paradoxy: Information society: perspectives, problems, paradox, LCA, Levice, 2006.

9 Vodák J, Kucharčíková A, Efektivní vzdělávání zaměstnanců: Effective education of employees, Grada Publishing, a.s., Praha, 2007. isbn=978-80-2473651-8.

10 profit, on-line, available at http://profit.etrend.sk/ ludia-a-udalosti/facebook-a-jeho-lepkave-prsty/164236. html

11 careerxroads, on-line, available at http://www.careerxroads.com/ about/index.asp

12 Robert Half International, on-line, available at http://www .rhi.com/

13 comScore, on-line, available at http://www.comscore.com/Press_ Events/Press_Releases/2009/1/Mobile_Social_Networking_ Europe/\%28language\%29/eng-US

14 letstalk, on-line: Mobile social networks value map. 